\title{
Development of a Social Contact Survey Instrument Relevant to the Spread of Infectious Disease and Its Application in a Pilot Study Among Korean Adults
}

\author{
Hyang Soon $\mathrm{Oh}^{1}$, Youngran Yang ${ }^{2}$, Mikyung Ryu ${ }^{3 *}$ \\ ${ }^{1}$ Department of Nursing, College of Life Science and Natural Resources, Sunchon National University, Suncheon, Korea; ${ }^{2}$ Research Institute of \\ Nursing Science, Jeonbuk National University College of Nursing, Jeonju, Korea; ${ }^{3}$ Graduate School of Education, Kyung Hee University, Seoul, Korea
}

Objectives: This study aimed to develop a valid social contact survey instrument and to verify its feasibility for use among Korean adults.

Methods: The Delphi technique was used to develop an instrument to assess social contacts, which was then applied in a cross-sectional pilot study. A panel of 15 medical professionals reviewed the feasibility and validity of each item. The minimum content validity ratio was 0.49 . Thirty participants used the developed measure to record contacts during a 24-hour period.

Results: After a systematic review, the survey instrument (parts I and II) was developed. Part I assessed social contact patterns over a 24-hour period, and part II assessed perceptions of contacts in daily life and preventive behaviors (hand hygiene and coughing etiquette). High validity and feasibility were found. In the pilot study, the 30 participants had a combined total of 198 contacts (mean, 6.6 daily contacts per person). The participants' age $(p=0.012)$, occupation $(p<0.001)$, household size $(p<0.001)$, education $(p<0.001)$, personal income $(p=0.003)$, and household income $(p<0.001)$ were significantly associated with the number of contacts. Contacts at home, of long duration, and of daily frequency were relatively likely to be physical. Assortative mixing was observed between individuals in their 20s and 50s. Contact type differed by location, duration, and frequency $(p<0.001)$.

Conclusions: The developed social contact survey instrument demonstrated high validity and feasibility, suggesting that it is viable for implementation.

Key words: Contact tracing, Cross-infection, Transmission of infection, Delphi technique, Validity, Feasibility

Received: September 5, 2019 Accepted: January 22, 2020

Corresponding author: Youngran Yang, PhD

Research Institute of Nursing Science, Jeonbuk National University

College of Nursing, 567 Baekje-daero, Deokjin-gu, Jeonju 54896,

Korea

E-mail: youngran13@jbnu.ac.kr

${ }^{*}$ Current affiliation: Department of Nursing, Daegu University, Daegu, Korea.

This is an Open Access article distributed under the terms of the Creative Commons Attribution Non-Commercial License (https://creativecommons.org/licenses/by$\mathrm{nc} / 4.0 /$ ) which permits unrestricted non-commercial use, distribution, and reproduction in any medium, provided the original work is properly cited.

\section{INTRODUCTION}

Contact between people plays an instrumental role in the direct spread of infectious diseases. Human contact patterns are fundamental to our understanding of the dynamics of infectious disease spread [1]. Put simply, an infectious disease that spreads from person to person cannot persist unless an infected person meets a susceptible one $[1,2]$. In terms of pathogens, this means that an infection that is readily spread through daily social contact does not have to last long, since an infectious person is almost certain to meet a susceptible individual within 1 day or 2 days [1]. It is not possible for each 
member of the population to have the same chance of meeting everyone else; instead, individuals are likely to have varying patterns of contact with one another. To gain a better understanding of the epidemiology of infectious diseases, we need to study these contact patterns, as they are important determinants of the spread of infectious disease. Moreover, the ability to predict infectious disease spread and the impact of interventions such as vaccinations depends on whether close contacts among individuals can be quantified. Understanding the nature of human contact patterns is crucial for predicting the impact of future pandemics and for devising effective control measures [2-4]. Presently, reporting systems in many countries measure the numbers and characteristics of contact patterns in the population with the goal of controlling the spread of infection [4-8]. Moreover, mathematical modeling of infectious diseases transmitted by respiratory or close-contact routes (e.g., pandemic influenza) is being increasingly used to predict epidemics and to determine the impact of possible interventions [5].

In 2015, an outbreak of Middle East Respiratory Syndrome (MERS) occurred in Korea. From the first case on May 20, 2015 to the official declaration of the cessation of MERS on December 23, 2015, a total of 186 cases were recorded; 38 deaths occurred (a mortality rate of 20.4\%), and a total of 16693 exposed individuals were isolated [9]. This MERS outbreak, which was predominantly spread by person-to-person contact, was highly costly to Korea.

It is always possible that emerging infectious diseases such as MERS will reemerge in Korea due to its high population density, global business expansion, and the increased frequency of air travel. Therefore, social contact patterns should be assessed when developing ways to effectively predict the transmission patterns and spread of infections. Additionally, we must assess the population's perceptions of contacts and infection transmission, as well as hand hygiene and coughing etiquette practices, when developing public education programs focused on prevention. For instance, hand hygiene and coughing etiquette are basic techniques that reduce the transmission of pathogens [10,11].

Few prior studies have investigated social contacts as it pertains to the dynamics of infectious disease spread, and no instrument that reflects Korean culture, daily life, and society has yet been developed.

The aims of this study were as follows. First, using the Delphi technique, we developed a social contact survey instrument that included assessments of perceptions of contacts in daily life, as well as hand hygiene practices and coughing etiquette. Second, we applied the newly developed instrument in a pilot study to assess its feasibility for assessing social contacts, perception, and adherence.

\section{METHODS}

This utilized a 2-stage methodology: the development of a valid social contact survey instrument and the verification of its feasibility for use through a survey of Korean adults. Therefore, this paper sequentially discusses the development of the instrument and the pilot study.

\section{Development of a Social Contact Survey Instrument Using the Delphi Technique Derivation of the questionnaire items}

A systematic review of the literature was conducted to extract relevant questionnaire items. The keywords were constructed as follows: (1) population (general population, healthcare workers, patients, visitors, providers, and students); (2) exposure (social, hand, face, mouth, environment, direct, indirect, and behavioral; through contact or touch); (3) comparison (hand hygiene and handwashing); and (4) outcome (infection, prevalence, transmission rate, and type, frequency, and mode of transmission). Studies were identified from the archives of PubMed, the Cochrane Library, Scopus, and KoreaMed. Only papers published in English or Korean between 2000 and 2017 were reviewed. The inclusion criteria were that the studies should be original and peer-reviewed, contain qualitative, quantitative, or mixed-research, and be related to the topic of contact. The instrument was developed by referring to the 12 studies that were finally chosen.

The selected studies were reviewed, and variables affecting contact in people's daily lives were identified. The social contact survey instrument similarly comprised 2 parts: part I contained a contact diary for assessing social contacts within a 24hour period ( 5 a.m. to 5 a.m. the next day), as contact diaries have been frequently used to record social contacts [1-8], while part II contained a questionnaire that assessed perceptions of contacts in daily life and practices of hand hygiene and coughing etiquette. Part I included 5 sections to be filled out by the participant: (I-1) number of family members; (I-2) place of residence; (I-3) information about family members; (I-4) information about the people with whom the participant had been in 
contact in the last 24 hours as well as the type, duration, location, and frequency of contacts; and (I-5) a request that the participant check the previous 4 entries for accuracy $[5,6]$. Part I-4 consisted of items that collected data about physical (e.g., skin-to-skin) contact, which is associated with the probable spread of infectious diseases, and non-physical contact, defined as face-to-face conversations consisting of 2 or 3 phrases with the interlocutors within 2-3 $\mathrm{m}$ of one another.

Part II consisted of the following components: perceptions of the possibility of transmission of infectious diseases due to contact with others (II-1) and contact with the environment (II-2), rated on a 10-point scale (1, definitely no; 10 , definitely yes); (II-3) perceptions of the preventive effects of personal hygiene (hand hygiene, coughing etiquette, and vaccination) using 4 subcategories on a 7-point scale (1, no effect; 7 , very effective) $[12,13]$; (II-4) perceptions of the necessity of hand hygiene, with 10 subcategories measured using responses of either yes (1) or no (0); (II-5) adherence to hand hygiene and coughing etiquette, with 11 subcategories rated on a 7-point scale $[12,13]$; (II-7) perceptions of susceptibility to infectious disease measured on a 10-point scale (1, no/very unhealthy; 10 , very much/very healthy) [14], and (II-8) perceptions of subjective health status measured on a 10-point scale (1, no/very unhealthy; and 10, very much/very healthy) [14]. Altogether, part II comprised 29 questions.

\section{Delphi method}

Two rounds of the Delphi technique were conducted to ensure the content validity and feasibility of this survey instrument. We decided to use panels of 15, as in Lawshe [15] and Lee [16] reports. Fifteen infection control experts who agreed to participate were recruited as panel members. The Delphi technique was carried out from December 1, 2017 to December 30,2017 . The average, median, and mode obtained from the first round were presented and sent via e-mail along with the results from the second round to ensure opportunities for correction.

\section{Measures and analysis}

The content validity of the questionnaire was analyzed via the content validity ratio (CVR), and the minimum CVR value across the 15 experts in this study was set as 0.49 , as proposed by Lawshe [15]. The Delphi technique panel responded on a 5-point Likert scale (1, strongly disagree; 2, disagree; 3, neutral; 4 , agree; and 5 , strongly agree). Items were classified as nega- tive (corresponding to a rating of 1-2), neutral (corresponding to a rating of 3), or positive (corresponding to a rating of 4-5). If an item was given a score of 4 or 5 , the item was considered acceptable. The mean, standard deviation (SD), CVR, and feasibility score in each round were calculated using MS Excel (Microsoft, Redmond, WA, USA) and SPSS version 24 (IBM Corp., Armonk, NY, USA).

\section{Pilot Study \\ Research design}

This study used a cross-sectional design and applied a survey instrument that was developed via the Delphi technique.

\section{Participants and data collection}

The participants were 30 adults over 20 years of age who were recruited locally using snowball sampling, mainly from 2 universities and a church. The participants indicated that they fully understood the purposes of the study, and recruitment was both voluntary and anonymous. Prior to participation, written informed consent was obtained from each participant. Participants were also informed that they could withdraw their consent at any time during the study. Participants were educated and trained on the use of a contact diary, and they were carefully instructed to prospectively collect information about their contacts during a 24-hour period ( 5 a.m. to 5 a.m. the next day) on a randomly selected day according to their convenience. Physical contact was defined as skin-to-skin contact, such as a handshake or a hug, and non-physical contact constituted conversations of more than 2 words or 3 words within 1-2 $\mathrm{m}$ of another individual. To facilitate the reproducibility and the accuracy of the data, the question "Is there anything missing in the contact record recorded above?" was included as the last question of the contact diary. It took each participant approximately 20 minutes to complete the questionnaire. The data were collected between January 14, 2018 and February 12, 2018.

\section{Data analysis}

Data analysis was conducted using SPSS version 24 (IBM Corp.). In detail, (1) descriptive statistics were utilized; (2) a scatter diagram was used to visualize the relationship between participant age and contact age; (3) contact patterns by participant age were analyzed in terms of the frequency, percentage, chisquare test, and Fisher exact test; (4) contact patterns were analyzed according to the general characteristics of participants using the $t$-test, Welch test, and Games-Howell test, and 
contact patterns were analyzed according to contact type, contact location, contact duration, and contact frequency using the chi-square test, Fisher exact test, and bar charts; and (5) perceptions of contacts in daily life and practices of hand hygiene and coughing etiquette were analyzed using the mean, $S D$, and analysis of variance. The score for each question was considered to be acceptable if the mean was 5 or higher on a 7-point Likert scale, 6 or higher on a 0-point to 9-point Likert scale, or 7 or higher on a 1-point to 10-point Likert scale in order to only count responses higher than neutral as acceptable. For item II-7, the perception of susceptibility to infectious disease was considered to be acceptable if the mean score was 4 or lower $[17,18]$. The Cronbach alpha was calculated as a measure of reliability.

\section{Ethics Statement}

The Delphi survey was exempted from review by the Institutional Review Board (IRB) of Konkuk University Medical Center (KUH1280109), and the pilot study was approved by the IRB of Sunchon National University (1040173-201712-HR-033-02).

\section{RESULTS}

\section{Development of a Social Contact Survey Instrument Using the Delphi Technique}

Fifteen expert panel members participated in the application of the Delphi technique. Their mean age was 42.1 years (SD, 4.4; 3 men and 12 women). All experts were actively employed at infection control departments, and the average length of their careers as infection control practitioners was 17.3 years (SD, 4.7).

Table 1. Results of the Delphi survey for the social contact survey instrument $(n=15)$

\begin{tabular}{|c|c|c|c|c|c|}
\hline \multirow{2}{*}{ Question item } & & \multicolumn{2}{|c|}{ First round } & \multicolumn{2}{|c|}{ Second round } \\
\hline & & Mean \pm SD & CVR & Mean \pm SD & CVR \\
\hline \multicolumn{6}{|l|}{ I. Contact diary instrument } \\
\hline I-1. How many family members (or cohabitees) live with you? & Feasibility & $4.9 \pm 0.3$ & 1.00 & $5.0 \pm 0.0$ & 1.00 \\
\hline \multirow[t]{2}{*}{ I-2. Where do you live? } & Validity & $4.7 \pm 0.5$ & 1.00 & $4.9 \pm 0.3$ & 1.00 \\
\hline & Feasibility & $4.8 \pm 0.4$ & 1.00 & $4.9 \pm 0.4$ & 1.00 \\
\hline I-3. Please fill in information about your family members (or your cohabitees) & Feasibility & $4.5 \pm 0.6$ & 0.87 & $4.7 \pm 0.5$ & 1.00 \\
\hline \multirow{2}{*}{$\begin{array}{l}\text { I-4. Please record the details of each contact that occurred between } 5 \text { a.m. } \\
\text { and } 5 \text { a.m. the next day }\end{array}$} & Validity & $4.4 \pm 1.1$ & 0.73 & $4.9 \pm 0.4$ & 1.00 \\
\hline & Feasibility & $3.6 \pm 1.1$ & 0.47 & $3.9 \pm 0.7$ & 0.47 \\
\hline \multirow{2}{*}{ I-5. Are all of your contacts recorded in the above contact diary? } & Validity & $4.1 \pm 1.1$ & 0.60 & $4.2 \pm 0.6$ & 0.87 \\
\hline & Feasibility & $3.9 \pm 1.1$ & 0.60 & $4.1 \pm 0.6$ & 0.73 \\
\hline $\begin{array}{l}\text { II-2. Do you think that infectious disease transmission can occur through } \\
\text { contact with the environment in everyday life? }\end{array}$ & Validity & $4.6 \pm 0.8$ & 0.87 & $4.7 \pm 0.8$ & 0.87 \\
\hline \multirow{3}{*}{$\begin{array}{l}\text { II-3. How effectively do you think personal hygiene practices (hand hygiene, } \\
\text { coughing etiquette, and vaccination) help in preventing the transmission } \\
\text { of infectious diseases? }\end{array}$} & Feasibility & $4.8 \pm 0.4$ & 1.00 & $4.8 \pm 0.4$ & 1.00 \\
\hline & Validity & $5.0 \pm 0.0$ & 1.00 & $5.0 \pm 0.0$ & 1.00 \\
\hline & Feasibility & $4.8 \pm 0.4$ & 1.00 & $4.9 \pm 0.3$ & 1.00 \\
\hline \multirow{2}{*}{$\begin{array}{l}\text { II-4. Please indicate whether the following situations require hand hygiene } \\
\text { to prevent the spread of infections by contact. }\end{array}$} & Validity & $4.9 \pm 0.3$ & 1.00 & $4.9 \pm 0.3$ & 1.00 \\
\hline & Feasibility & $4.9 \pm 0.4$ & 1.00 & $4.9 \pm 0.4$ & 1.00 \\
\hline \multirow{2}{*}{$\begin{array}{l}\text { II-5. How often do you usually adhere to hand hygiene and coughing } \\
\text { etiquette in the following situations? }\end{array}$} & Validity & $4.9 \pm 0.3$ & 1.00 & $5.0 \pm 0.0$ & 1.00 \\
\hline & Feasibility & $4.7 \pm 0.6$ & 0.87 & $4.9 \pm 0.4$ & 1.00 \\
\hline \multirow{2}{*}{$\begin{array}{l}\text { II-6. Please place a check-mark (y) in the box below if you have had } \\
\text { experience with personal hygiene tips (regarding hand hygiene, } \\
\text { coughing etiquette, or vaccination) through media and promotional } \\
\text { materials in the past year. }\end{array}$} & Validity & $4.5 \pm 0.5$ & 1.00 & $4.9 \pm 0.3$ & 1.00 \\
\hline & Feasibility & $4.7 \pm 0.5$ & 1.00 & $4.7 \pm 0.5$ & 1.00 \\
\hline
\end{tabular}

SD, standard deviation; CVR, content validity ratio. 


\section{Results of the first round}

The CVR scores for all items but 1 were above the minimum value (0.49) during the first round (Table 1). The item with a low CVR (0.47) for feasibility was I-4: "Please record the details of each contact you have had from 5 a.m. to 5 a.m. the next day" (Table 1). Based on opinions derived during the first round, the following refinements were made. For the contact types covered in $\mathrm{I}-4$, there was a request for additional examples of non-physical contact; thus, we included several examples of both non-physical and physical contact. Further requests for other item revisions (I-4, I-5, II-11, and II-12) were also addressed.

\section{Results of the second round}

A content validity assessment after the second round demonstrated that the CVR scores for all items were 0.49 or greater. The CVR for the feasibility of I-4 (0.47) was the same as in the first round, but the CVR for validity and the mean of the Likert scale increased to 1.00 and 4.90 , respectively (Table 1 ). The other questionnaire items showed that the CVR for both validity and feasibility, as well as the mean of the Likert scale, increased compared to the first round, including the revised items (I-4, I-5, II-11, and II-12).

\section{Pilot Study}

\section{General characteristics of the participants}

Participants in their 20s accounted for $43.3 \%$ of all participants (mean age, 41.0 years); $63.3 \%$ of participants were female, $44.8 \%$ were high school graduates, $36.7 \%$ were university students, and $48.3 \%$ had personal monthly incomes under 2 million Korean won (KRW).

\section{Contact differences by participants' characteristics}

Over a 24-hour period, the 30 participants recorded a total of 198 contacts, with a mean of 6.6 contacts per participant per day (range, 0-18).

The participants' age $(p=0.012)$, occupation $(p<0.001)$, household size $(p<0.001)$, education $(p<0.001)$, personal income $(p=0.003)$, and household income $(p<0.001)$ were significantly associated with the number of contacts according to the Welch test. The numbers of contacts were highest among those over 60 years of age $(11.1 \pm 7.5)$, in households with 3 members (11.2 \pm 5.4$)$, with college-level educations (11.9 \pm 4.2), with a personal income between 2 million KRW and 4 million KRW (9.4 \pm 4.9$)$, and with a household income of more
Table 2. Differences in contacts according to participants' characteristics

\begin{tabular}{|c|c|c|c|c|c|}
\hline \multirow[t]{2}{*}{$\begin{array}{l}\text { Characteris- } \\
\text { tics }\end{array}$} & $\begin{array}{c}\text { Participants } \\
(\mathbf{n}=\mathbf{3 0})\end{array}$ & $\begin{array}{l}\text { Contacts } \\
(n=198)\end{array}$ & \multirow{2}{*}{$\begin{array}{l}\text { Games- } \\
\text { Howell }\end{array}$} & \multirow[t]{2}{*}{$\mathbf{t} / \mathbf{F}$} & \multirow{2}{*}{$\begin{array}{c}p \text { - } \\
\text { value }\end{array}$} \\
\hline & $n(\%)$ & Mean \pm SD & & & \\
\hline \multicolumn{6}{|l|}{ Sex ${ }^{1}$} \\
\hline Male & $11(36.7)$ & $9.1 \pm 4.6$ & - & 3.032 & 0.083 \\
\hline Female & 19 (63.3) & $10.2 \pm 5.1$ & & & \\
\hline \multicolumn{6}{|l|}{ Age (y) } \\
\hline $20-29^{a}$ & $13(43.3)$ & $10.3 \pm 4.7$ & $c>b$ & 4.561 & 0.012 \\
\hline $30-59^{b}$ & $10(33.3)$ & $8.4 \pm 2.9$ & & & \\
\hline$\geq 60^{\circ}$ & $7(23.3)$ & $11.1 \pm 7.5$ & & & \\
\hline \multicolumn{6}{|l|}{ Occupation ${ }^{2}$} \\
\hline None $^{\mathrm{a}}$ & $5(16.7)$ & $2.2 \pm 0.6$ & $b, c, d>a$ & 28.257 & $<0.001$ \\
\hline Student ${ }^{\mathrm{b}}$ & $11(36.7)$ & $7.1 \pm 2.4$ & $c>b, e, f$ & & \\
\hline Officer $^{\mathrm{C}}$ & $5(16.7)$ & $13.5 \pm 3.6$ & $f>b, e$ & & \\
\hline Sales/service ${ }^{d}$ & $1(3.3)$ & $10.0 \pm 0.0$ & & & \\
\hline $\begin{array}{l}\text { Health care } \\
\text { provider }^{\mathrm{e}}\end{array}$ & $1(3.3)$ & $3.0 \pm 0.0$ & & & \\
\hline Other ${ }^{f}$ & $7(23.3)$ & $10.9 \pm 5.6$ & & & \\
\hline \multicolumn{6}{|l|}{ Household size ${ }^{2}$} \\
\hline $1^{\text {a }}$ & $4(13.3)$ & $5.9 \pm 2.5$ & $c, d>a$ & 6.806 & $<0.001$ \\
\hline $2^{\mathrm{b}}$ & $11(36.7)$ & $8.4 \pm 4.7$ & $c>b$ & & \\
\hline $3^{c}$ & $8(26.7)$ & $11.2 \pm 5.4$ & & & \\
\hline $4^{d}$ & $6(20.0)$ & $11.0 \pm 4.7$ & & & \\
\hline $5^{e}$ & $1(3.3)$ & $0.0 \pm 0.0$ & & & \\
\hline \multicolumn{6}{|l|}{ Education $^{2}$} \\
\hline Secondary ${ }^{a}$ & $2(6.9)$ & $2.6 \pm 0.5$ & $c, d>b>a$ & 25.735 & $<0.001$ \\
\hline High school ${ }^{\mathrm{b}}$ & $13(44.8)$ & $6.8 \pm 2.7$ & & & \\
\hline College $^{\mathrm{c}}$ & $8(27.6)$ & $11.9 \pm 4.2$ & & & \\
\hline Graduate $^{d}$ & $6(20.7)$ & $11.5 \pm 5.5$ & & & \\
\hline \multicolumn{6}{|c|}{ Personal income $\left(10^{4} \mathrm{KRW}\right)^{2}$} \\
\hline$<200^{\mathrm{a}}$ & $14(48.3)$ & $9.0 \pm 5.0$ & $b, c>d$ & 4.766 & 0.003 \\
\hline $200-300^{b}$ & $6(20.7)$ & $9.4 \pm 4.9$ & & & \\
\hline $300-400^{c}$ & $4(13.8)$ & $9.4 \pm 2.0$ & & & \\
\hline$\geq 400^{d}$ & $5(17.2)$ & $2.3 \pm 5.5$ & & & \\
\hline \multicolumn{6}{|c|}{ Household income $\left(10^{4} \mathrm{KRW}\right)^{2}$} \\
\hline$<200^{\mathrm{a}}$ & $3(10.7)$ & $6.3 \pm 3.0$ & $f>a, b, c, d, e$ & 20.729 & $<0.001$ \\
\hline $200-300^{b}$ & $4(14.3)$ & $3.6 \pm 1.2$ & $d>b$ & & \\
\hline $300-400^{c}$ & $4(14.3)$ & $11.9 \pm 5.1$ & $c, f>a, d$ & & \\
\hline $400-500^{d}$ & $4(14.3)$ & $8.5 \pm 2.2$ & $f>e>b$ & & \\
\hline $500-1000^{e}$ & $11(39.3)$ & $9.6 \pm 3.8$ & $c>a, b$ & & \\
\hline$\geq 1000^{f}$ & $2(7.1)$ & $15.9 \pm 5.4$ & & & \\
\hline
\end{tabular}

SD, standard deviation; KRW, Korean won.

${ }^{1}$ t-test.

${ }^{2}$ Welch test, Games-Howell post hoc test (both the Welch and Games-Howell tests were performed because the assumption of normality was satisfied but the homoscedasticity was not satisfactory). 
than 10 million KRW (15.9 \pm 5.4$)$ according to the Games-Howell post hoc test (Table 2).

\section{Analysis of contacts by participants' age}

The most contacts were reported by those aged 51-55 (18.4\%), followed by those aged 26-30 (16.3\%). Among other

Table 3. Characteristics of contacts according to participants' age (participants, $n=30$; contacts, $n=198$ )

\begin{tabular}{|c|c|c|c|c|c|c|}
\hline \multirow{2}{*}{ Characteristics } & & \multicolumn{4}{|c|}{ Participants' age (y) } & \multirow{2}{*}{$\begin{array}{c}\text { Pearson } \chi^{2} \\
(p \text {-value })\end{array}$} \\
\hline & & Total $^{1}$ & $20-29$ & $30-59$ & $\geq 60$ & \\
\hline \multirow[t]{11}{*}{ Age (y) } & $\leq 20$ & $16(8.2)$ & $6(37.5)$ & 10 (62.5) & $0(0.0)$ & $76.462(<0.001)$ \\
\hline & $21-25$ & $23(11.7)$ & 18 (73.8) & $4(17.4)$ & $1(4.3)$ & \\
\hline & $26-30$ & $32(16.3)$ & $23(71.9)$ & $5(15.6)$ & $4(12.5)$ & \\
\hline & $31-35$ & $16(8.2)$ & $9(56.3)$ & $4(25.0)$ & $3(18.8)$ & \\
\hline & $36-40$ & $4(2.0)$ & $2(50.0)$ & $2(50.0)$ & $0(0.0)$ & \\
\hline & $41-45$ & $15(7.7)$ & $5(33.3)$ & $8(53.3)$ & $2(13.3)$ & \\
\hline & $46-50$ & $21(10.7)$ & $3(14.3)$ & $14(66.7)$ & $4(19.0)$ & \\
\hline & $51-55$ & $36(18.4)$ & $25(69.4)$ & $8(22.2)$ & $3(8.3)$ & \\
\hline & $56-60$ & $15(7.7)$ & $6(40.0)$ & $2(13.3)$ & $7(46.7)$ & \\
\hline & $61-65$ & $8(4.1)$ & $1(12.5)$ & $3(37.5)$ & $4(50.0)$ & \\
\hline & $\geq 66$ & $10(5.1)$ & $0(0.0)$ & $6(60.0)$ & $4(40.0)$ & \\
\hline \multirow[t]{2}{*}{ Sex } & Male & 75 (39.1) & $29(38.7)$ & $30(40.0)$ & $16(21.3)$ & $4.244(0.120)$ \\
\hline & Female & $117(60.9)$ & $63(53.8)$ & $36(30.8)$ & $18(15.4)$ & \\
\hline \multirow[t]{5}{*}{ Group to which contact belongs } & Family & $54(27.6)$ & $21(38.9)$ & $24(44.4)$ & $9(16.7)$ & $14.318(0.126)^{2}$ \\
\hline & Dormitory & $2(1.0)$ & $1(50.0)$ & $1(50.0)$ & $0(0.0)$ & \\
\hline & School & $10(5.1)$ & $4(40.0)$ & $6(60.0)$ & $0(0.0)$ & \\
\hline & Work & 70 (35.7) & $40(57.1)$ & $15(21.4)$ & $15(21.4)$ & \\
\hline & Other ${ }^{3}$ & $60(30.6)$ & $31(51.7)$ & $19(31.7)$ & $10(16.7)$ & \\
\hline \multirow[t]{2}{*}{ Type of contact } & Physical & $59(29.8)$ & $21(35.6)$ & 31 (52.5) & $7(11.9)$ & $13.963(0.001)$ \\
\hline & Non-physical & $139(70.2)$ & $77(55.4)$ & $35(25.2)$ & $27(19.4)$ & \\
\hline \multirow[t]{5}{*}{ Duration of contact } & $<5 \min$ & $37(18.8)$ & $17(45.9)$ & $12(32.4)$ & $8(21.6)$ & $11.936(0.154)$ \\
\hline & 5-14 min & $17(8.6)$ & $6(35.3)$ & $8(47.1)$ & $3(8.6)$ & \\
\hline & $15-59 \min$ & $36(18.3)$ & $19(52.8)$ & $12(33.3)$ & $5(13.9)$ & \\
\hline & $1-4 \mathrm{hr}$ & $52(26.4)$ & 35 (67.3) & $11(21.2)$ & $6(11.5)$ & \\
\hline & $>4 \mathrm{hr}$ & $55(27.9)$ & $21(38.2)$ & $23(41.8)$ & $11(20.0)$ & \\
\hline \multirow[t]{5}{*}{ Location of contact } & Home & $61(31.1)$ & $23(37.7)$ & $28(45.9)$ & $10(16.4)$ & $16.751(0.016)^{2}$ \\
\hline & Work & $62(31.6)$ & $38(61.3)$ & 12 (19.4) & $12(19.4)$ & \\
\hline & School & $6(3.1)$ & $4(66.7)$ & $0(0.0)$ & 2 (33.3) & \\
\hline & Transportation & $3(1.5)$ & $2(66.7)$ & $0(0.0)$ & $1(33.3)$ & \\
\hline & Other ${ }^{4}$ & $64(32.7)$ & $30(46.9)$ & $25(39.1)$ & $9(14.1)$ & \\
\hline \multirow[t]{5}{*}{ Frequency of contact } & Daily & $84(42.9)$ & $42(50.0)$ & $32(38.1)$ & $10(11.9)$ & $27.402(0.001)$ \\
\hline & 1-2 times/wk & $62(31.6)$ & $38(61.3)$ & $11(17.7)$ & $13(21.0)$ & \\
\hline & 1-2 times/mo & $18(9.2)$ & $9(50.0)$ & $8(44.4)$ & $1(5.6)$ & \\
\hline & $<1$ time/mo & $17(8.7)$ & $3(17.6)$ & $12(70.6)$ & $2(11.8)$ & \\
\hline & Never met before & $15(7.7)$ & $6(40.0)$ & $3(20.0)$ & $6(40.0)$ & \\
\hline \multirow[t]{2}{*}{ Day of contact } & Weekday & $99(50.0)$ & 62 (62.6) & $19(19.2)$ & $18(18.2)$ & $19.935(<0.001)$ \\
\hline & Weekend & $99(50.0)$ & $36(36.4)$ & 47 (47.5) & $16(16.2)$ & \\
\hline
\end{tabular}

Values are presented as number (\%).

${ }^{1}$ There is a place where the contact information is missing.

${ }^{2}$ Fisher exact test.

${ }^{3}$ Includes members of groups not previously listed (e.g., neighbor, cashier, physician, etc.).

${ }^{4}$ Includes locations not belonging to the previously listed categories (e.g., leisure, shopping, clinic, etc.). 
categories, the highest contact frequencies were as follows: female contacts (60.9\%); employed individuals (35.7\%); nonphysical contact (70.2\%); more than 4 hours of contact duration (27.9\%), followed by 1-4 hours of contact duration (26.4\%); contact at "other" locations (32.7\%), followed by at the workplace (31.6\%) and then at home (31.1\%); daily contacts (42.9\%); and weekend contacts (50.0\%) (Table 3).

The distributions of contacts in terms of age $(p<0.001)$, type $(p=0.001)$, location $(p=0.016)$, frequency $(p=0.001)$, and days of occurrence $(p<0.001)$ differed according to the participants' age groups. Participants who were $20-29$ years of age had a large number of non-physical contacts; the 30-59-year-old participants had a large number of physical contacts; the 2029-year-old participants had a large number of contacts at work; and the 30-59-year-old participants as well as those 60 or older had a large number of contacts at home. The participants and their contacts showed assortative mixing of participants in their 20s with people in their 20s and 50s (Supplemental Material 1).

\section{Contact patterns: type, location, duration, frequency, and relationships}

Contact type differed by location, duration, and frequency $(p<0.001)$. Physical contact was most frequent at home (55.7\%), followed by other locations (21.9\%) and the workplace (17.7\%) (Figure 1A). Physical contact was most frequent at a duration of over 4 hours $(61.8 \%)$, followed by $1-4$ hours (32.7\%) and 15 59 minutes (19.4\%), respectively (Figure 1B). Physical contact

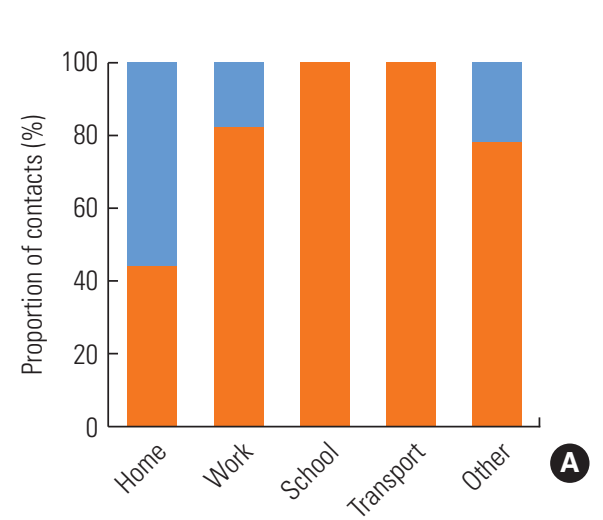

Location

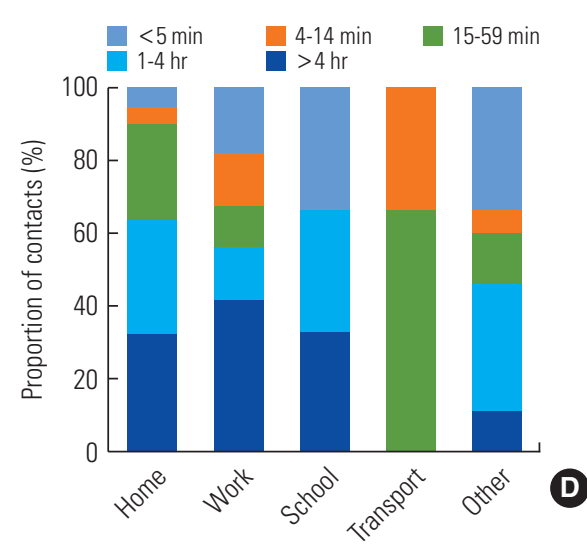

Location
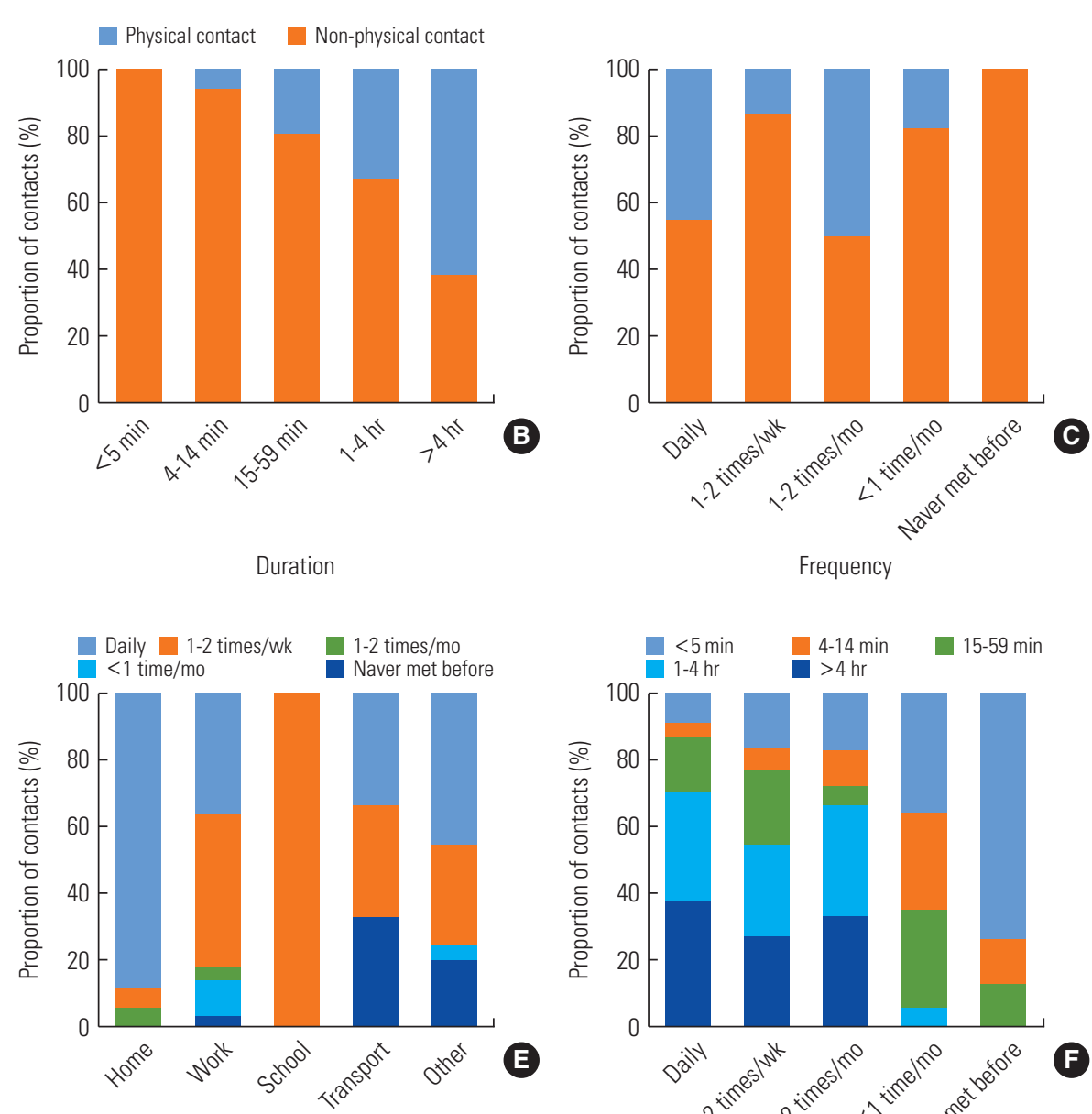

Location

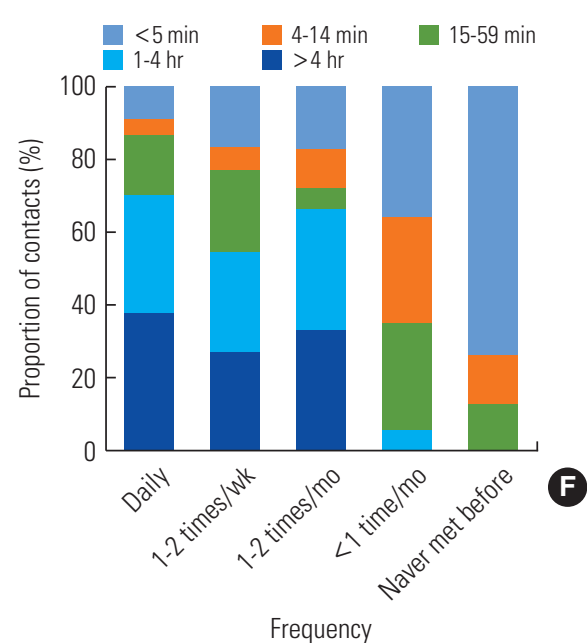

Figure 1. The proportion of contacts that involved physical contact by duration, location, and frequency of contact. Graphs show data by location (A), duration (B), and frequency of contacts (C); the correlation between location and duration of contact (D), between location and frequency of contact $(\mathrm{E})$, between frequency and duration of contact $(\mathrm{F})$ are shown. All correlations were highly significant $\left(p<0.001, \chi^{2}\right.$-test) $\left(A, \chi^{2}=30.832 ; B, \chi^{2}=53.427 ; C, \chi^{2}=30.431 ; D, \chi^{2}=48.953 ; E, \chi^{2}=61.719 ; F, \chi^{2}=66.031\right)$. 
was most commonly reported to occur 1 time or 2 times per month (50.0\%), followed by daily (45.2\%) (Figure 1C). Contact duration differed by location $(p<0.001)$; contact duration greater than 4 hours was most frequent at home (32.8\%), followed by work (41.9\%) and school (33.3\%), respectively (Figure 1D). Contact frequency also showed a significant relationship with location ( $p<0.001$ ); nearly $75 \%$ of contacts occurred on a daily basis at home, followed by at the workplace (38.7\%) and in transportation (33.3\%), respectively (Figure 1E). Contact duration also showed a statistically significant relationship with frequency $(p<0.001)$; the greater the frequency, the longer the duration of contact (Figure 1F).

\section{Analysis of perceptions and adherence}

The reliability (Cronbach alpha) of the 11 items dealing with adherence to hand hygiene and coughing etiquette was 0.828 , and the reliability (Cronbach alpha) of the 29 total items was 0.797. Perceptions of the preventive effects of infectious disease through the use of coughing etiquette (II-3) and health status (II-8) had scores that were lower than acceptable. Adherence (II-5) to hand hygiene after sneezing, coughing, or blowing one's nose and coughing etiquette by wearing a mask when having a cold or respiratory symptoms also had lower than acceptable scores. Some noteworthy trends in the scores of each question according to age group were as follows. The perception of the possibility of infectious disease transmission by contact (II-2) with the environment had the highest score

Table 4. Analysis of scores on items dealing with participants' perceptions and adherence $(n=30)$

\begin{tabular}{|c|c|c|c|c|c|c|}
\hline \multirow{2}{*}{ Question ${ }^{1}$} & & \multirow{2}{*}{ Total } & \multicolumn{3}{|c|}{ Participants' age (y) } & \multirow{2}{*}{$\begin{array}{l}p \text {-value } \\
\text { (ANOVA) }\end{array}$} \\
\hline & & & $20-29$ & $30-59$ & $\geq 60$ & \\
\hline \multicolumn{2}{|c|}{$\begin{array}{l}\text { B-1. Do you think that infectious disease transmission can occur through contact with other } \\
\text { people in your daily life? }(1-10)\end{array}$} & $8.4 \pm 2.3$ & $8.2 \pm 1.5$ & $8.8 \pm 2.8$ & $8.4 \pm 3.0$ & 0.811 \\
\hline \multicolumn{2}{|c|}{$\begin{array}{l}\text { B-2. Do you think that infectious disease transmission can occur through contact with the } \\
\text { environment in everyday life? }(1-10)\end{array}$} & $8.0 \pm 2.5$ & $7.8 \pm 1.7$ & $9.4 \pm 1.0$ & $6.3 \pm 3.9$ & 0.029 \\
\hline \multirow{5}{*}{$\begin{array}{l}\text { B-3. How effective do you } \\
\text { think personal hygiene } \\
\text { practices are in the } \\
\text { prevention of the } \\
\text { transmission of infec- } \\
\text { tious diseases? }\end{array}$} & Hand hygiene & $6.2 \pm 1.2$ & $5.9 \pm 1.5$ & $6.1 \pm 1.0$ & $6.9 \pm 0.4$ & 0.185 \\
\hline & Avoidance of touching the eyes, nose, or mouth & $5.9 \pm 0.9$ & $5.7 \pm 1.0$ & $5.7 \pm 0.8$ & $6.7 \pm 0.8$ & 0.038 \\
\hline & Coughing etiquette & $4.9 \pm 1.9$ & $5.3 \pm 1.4$ & $4.9 \pm 1.5$ & $4.1 \pm 3.0$ & 0.440 \\
\hline & Wearing a mask when one has a cold or respiratory symptoms & $5.6 \pm 1.4$ & $5.3 \pm 1.6$ & $5.8 \pm 1.1$ & $6.0 \pm 1.2$ & 0.507 \\
\hline & Vaccination & $6.0 \pm 1.1$ & $6.0 \pm 0.9$ & $5.8 \pm 0.9$ & $6.3 \pm 1.5$ & 0.660 \\
\hline $\begin{array}{l}\text { B-4. Please indicate whether } \\
\text { the following situations } \\
\text { require hand hygiene } \\
\text { to prevent the spread of } \\
\text { disease by contact. }\end{array}$ & $\begin{array}{l}\text { After using the toilet; before and after food intake; before and } \\
\text { after cooking, before and after taking care of the ill; after } \\
\text { changing a diaper or cleaning children using the toilet; after } \\
\text { contact with wounds; after sneezing, coughing or blowing one's } \\
\text { nose; after contacting waste or trash; after contacting animals, } \\
\text { feed, or animal waste (0-9) }\end{array}$ & $8.8 \pm 0.5$ & $8.7 \pm 0.8$ & $8.9 \pm 0.3$ & $9.0 \pm 0.0$ & 0.428 \\
\hline \multirow{11}{*}{$\begin{array}{l}\text { B-5. How often do you } \\
\text { usually perform hand } \\
\text { hygiene and cough } \\
\text { etiquette in the } \\
\text { following situations? }\end{array}$} & After using the toilet & $6.6 \pm 0.6$ & $6.7 \pm 0.6$ & $6.7 \pm 0.5$ & $6.4 \pm 0.8$ & 0.619 \\
\hline & Before and after food intake & $6.0 \pm 0.9$ & $5.4 \pm 0.8$ & $6.1 \pm 0.9$ & $6.9 \pm 0.4$ & 0.001 \\
\hline & Before and after cooking & $6.4 \pm 1.3$ & $6.2 \pm 1.7$ & $6.4 \pm 1.0$ & $6.9 \pm 0.4$ & 0.579 \\
\hline & Before and after taking care of the ill & $5.9 \pm 1.6$ & $5.6 \pm 1.5$ & $5.4 \pm 2.0$ & $7.0 \pm 0.0$ & 0.090 \\
\hline & After changing a diaper or cleaning children using the toilet & $6.0 \pm 1.9$ & $5.3 \pm 2.1$ & $6.2 \pm 1.9$ & $7.0 \pm 0.0$ & 0.170 \\
\hline & After contact with wounds & $5.7 \pm 1.6$ & $5.1 \pm 1.5$ & $6.0 \pm 1.8$ & $6.4 \pm 1.1$ & 0.152 \\
\hline & After sneezing, coughing, or blowing one's nose & $4.6 \pm 1.7$ & $3.9 \pm 1.5$ & $4.5 \pm 2.0$ & $5.9 \pm 1.2$ & 0.053 \\
\hline & After contacting waste or trash & $6.3 \pm 1.2$ & $6.3 \pm 0.9$ & $5.8 \pm 1.8$ & $6.9 \pm 0.4$ & 0.221 \\
\hline & After contacting animals, feed, animal waste, etc. & $6.2 \pm 1.5$ & $6.2 \pm 1.5$ & $5.9 \pm 1.9$ & $6.9 \pm 0.4$ & 0.423 \\
\hline & $\begin{array}{l}\text { Coughing etiquette: covering the face and nose with a tissue and } \\
\text { using a kerchief or clothing sleeve when coughing or sneezing }\end{array}$ & $6.0 \pm 0.8$ & $5.9 \pm 0.8$ & $6.2 \pm 0.8$ & $6.0 \pm 0.8$ & 0.582 \\
\hline & Wearing a mask when one has a cold or respiratory symptoms & $4.5 \pm 2.0$ & $4.8 \pm 1.8$ & $3.8 \pm 2.2$ & $4.9 \pm 2.0$ & 0.433 \\
\hline \multicolumn{2}{|c|}{ B-7. Do you think you are vulnerable to infectious diseases? (1-10) } & $4.9 \pm 2.8$ & $4.5 \pm 2.6$ & $4.0 \pm 2.5$ & $7.0 \pm 2.8$ & 0.072 \\
\hline \multicolumn{2}{|c|}{ B-8. How do you feel about your health over the past year? (1-10) } & $6.9 \pm 2.6$ & $6.9 \pm 2.1$ & $7.6 \pm 2.6$ & $5.9 \pm 3.2$ & 0.404 \\
\hline
\end{tabular}

Values are presented as mean \pm standard deviation.

ANOVA, analysis of variance.

${ }^{1}$ Unless otherwise indicated, items have a range of 1-7. 
$(p=0.029)$ in the 30-59-year age group (9.4 points). Perceptions of the preventive effects (II-3) of not touching one's eyes, nose, or mouth by hand $(p=0.038)$, as well as hand hygiene and cough etiquette adherence (II-5) before and after eating ( $p=$ 0.001), were highest in those over 60 (Table 4).

\section{DISCUSSION}

The Delphi technique showed that the social contact survey instrument developed in this study was valid and feasible. During the first Delphi survey, the CVR scores for all questionnaire items revealed high levels of validity and feasibility, and the panel members concurred and strongly agreed with all but 1 questionnaire item. After the questionnaire was improved based on the expert panel's opinions prior to the second Delphi survey, the CVR validity and feasibility scores improved, further indicating the suitability of this study instrument. During the first and second rounds, only item A-4 ("Please record the details of each contact you have had from 5 a.m. to 5 a.m. the next day") had a low (VR for feasibility; however, its CVR for validity was high. Moreover, the CVR for the validity of item A-4 improved from 0.73 to 1.00 during the second round, supporting the questionnaire's validity. As a result, the social contact survey instrument developed in this study was found to be highly appropriate for use in research.

A pilot study conducted with this instrument found many significant social contact patterns. The participants came into contact with an average of 6.6 persons during a 24-hour period. Previous studies have shown that there were 8.0 daily contacts per person in France [8], 8.3 in Taiwan [19], 6.93 in Hong Kong [6], 10 in China [20], 15.3 in Japan [4], and 13.4 in 8 European countries [5]. A limitation of this present study is that it uses simple comparisons; however, it is still possible to apply this information to the number of contacts in Korea.

Contact patterns in terms of type, duration, location, and frequency differed by the participants' age. The 20-29-year age group had a large number of contacts that were non-physical, 1-4 hours in duration, at work, and 1-2 times/wk. The 30-59year age group had a large number of contacts that were physical, longer than 4 hours, and at home. These results are consistent with those of previous studies $[5,6]$. Participants in their 20s had a high frequency of contact with their peers (assortative mixing) and with those in their 50s, which is their parental generation. This result is consistent with findings of age- assortative mixing of those 5-20 years of age in Hong Kong [6], and of persons 5-24 years of age in Europe [5]. Participants in their 20s could spread infectious diseases if an outbreak occurs, and they should therefore be included in infection prevention strategies.

Physical contact was relatively frequent at home, with a long duration of contact ( $>4$ hours) and daily frequency, which is consistent with the results of previous studies [4$6,8,16]$. Infection transmission can occur in the home, so it is very important to meticulously practice the principles of personal hygiene (hand hygiene and coughing etiquette) at home first. There was a broad distribution of contact with a duration greater than 4 hours at home, work, and school. Daily contact frequency at home and 1-2 times/wk contact frequency at work was most common, and a contact duration greater than 4 hours was most common among contacts that occurred with high frequency.

Patterns of contact varied according to the participants' age, occupation, education, household size, personal income, and household income. Among those in their 20s, the higher the number of household members, education level, personal income, or household income, the higher the number of contacts $(p<0.05)$. These results are consistent with those of previous studies $[4-8,19]$.

Part II of our instrument showed a high level of reliability. Perceptions of the preventive effects of coughing etiquette (II-3), and hand hygiene adherence (II-5) after sneezing, coughing, or blowing one's nose, as well as coughing etiquette via wearing a mask when having a cold or respiratory symptoms, should be specifically addressed through public education. Education on the possibility of transmission of infectious diseases by contact (II-2) with the environment; the preventive effects on infectious disease transmission (II-3) of not touching one's eyes, nose, or mouth by hand; and hand hygiene and cough etiquette adherence (II-5) before and after eating should be specifically directed towards those 20-29 years of age.

In summary, social contact patterns varied according to age group in terms of contact time, place, type, and frequency, and adults in their 20 s exhibited an assortative mixing pattern. Contacts at home, of long duration, and of daily frequency were relatively likely to be physical. The number of contacts varied according to participants' age, occupation, household size, education, and income. These findings - the first such findings pertaining to Korea-are meaningfully consistent with those 
of previous studies in other countries $[4-8,18,19]$.

This study has limitations regarding the generalizability of its results because this is the first attempt to develop a research instrument of this nature [5] and to measure its applicability in a pilot study using a small number of participants $(n=30)$. Nonetheless, there were many significant findings. In order to identify more representative infection transmission patterns, it is necessary to promote research into social contacts on a nationwide scale.

The instrument developed in this study [21] can be used to quantify social contacts in Korea in a standardized way and to identify patterns according to population-level characteristics. Understanding the relationships between patterns of individual practices of hand hygiene and coughing etiquette can be used to develop guidelines for limiting the spread of infectious diseases. In this pilot study, many novel significant findings regarding social contact patterns in Korea were obtained. To establish a more generalized picture of social contact patterns and to develop an effective preventive strategy against infection transmission, a large-scale nationwide study should be carried out.

\section{SUPPLEMENTAL MATERIALS}

Supplemental material is available at https://doi.org/10. 3961/jpmph.19.251.

\section{CONFLICT OF INTEREST}

The authors have no conflicts of interest associated with the material presented in this paper.

\section{FUNDING}

This research was supported by research funding (code \#2017P140300) from the Korea Centers for Disease Control and Prevention.

\section{ACKNOWLEDGEMENTS}

The authors would like to thank those who participated in this survey, as well as Yun Sook Kim and Myong Jin Shin, who assisted with this study.

\section{AUTHOR CONTRIBUTIONS}

Conceptualization: HSO. Data curation: YY, MR. Formal analysis:YY, MR. Funding acquisition: HSO. Methodology: HSO. Project administration: HSO. Writing - original draft: HSO, YY, MR. Writing - review \& editing: HSO, YY, MR.

\section{ORCID}

Hyang Soon Oh https://orcid.org/0000-0002-5709-2861

Youngran Yang https://orcid.org/0000-0001-5610-9310

Mikyung Ryu https://orcid.org/0000-0002-9915-3175

\section{REFERENCES}

1. Giesecke J. Modern infectious disease epidemiology. 2nd ed. Sevenoaks: Hodder and Stoughton; 2002, p. 200-214.

2. Read JM, Eames KT, Edmunds WJ. Dynamic social networks and the implications for the spread of infectious disease. J R Soc Interface 2008;5(26):1001-1007.

3. Read JM, Edmunds WJ, Riley S, Lessler J, Cummings DA. Close encounters of the infectious kind: methods to measure social mixing behaviour. Epidemiol Infect 2012;140(12):2117-2130.

4. Ibuka Y, Ohkusa Y, Sugawara T, Chapman GB, Yamin D, Atkins $\mathrm{KE}$, et al. Social contacts, vaccination decisions and influenza in Japan. J Epidemiol Community Health 2016;70(2):162-167.

5. Mossong J, Hens N, Jit M, Beutels P, Auranen K, Mikolajczyk R, et al. Social contacts and mixing patterns relevant to the spread of infectious diseases. PLoS Med 2008;5(3):e74.

6. Leung K, Jit M, Lau EH, Wu JT. Social contact patterns relevant to the spread of respiratory infectious diseases in Hong Kong. Sci Rep 2017;7(1):7974.

7. Kretzschmar M, Mikolajczyk RT. Contact profiles in eight European countries and implications for modelling the spread of airborne infectious diseases. PLoS One 2009;4(6):e5931.

8. Béraud G, Kazmercziak S, Beutels P, Levy-Bruhl D, Lenne X, Mielcarek N, et al. The French connection: the first large populationbased contact survey in France relevant for the spread of infectious diseases. PLoS One 2015;10(7):e0133203.

9. Korea Centers for Disease Control and Prevention. 2015 MERS white book [cited $2018 \mathrm{Jul}$ 20]. Available from: http://www. cdc.go.kr/CDC/cms/content/mobile/39/70039_view.html (Korean).

10. Centers for Disease Control and Prevention. When and how to wash your hands [cited 2018 Aug 22]. Available from: https:// 
www.cdc.gov/handwashing/when-how-handwashing.html.

11. Centers for Disease Control and Prevention. Coughing \& sneezing [cited 2018 Aug 22]. Available from: https://www.cdc.gov/ healthywater/hygiene/etiquette/coughing_sneezing.html.

12. World Health Organization. Hand hygiene knowledge questionnaire for health-care workers; 2009 [cited 2017 Dec 22]. Available from: http://www.who.int/entity/gpsc/5may/Hand_ Hygiene_Knowledge_Questionnaire.doc?ua $=1$.

13. World Health Organization. Perception survey for health-care workers; 2009 [cited 2017 Dec 22]. Available from: http://www. who.int/entity/gpsc/5may/Perception_Survey_for_Health_ care_Workers.doc?ua $=1$.

14. Kim JH, Lee EH, Hyun HJ, Gil JH, Kim JS, Park YS, et al. A study of the affecting factors on the health promoting behaviors of the clinical nurses. J Korean Biol Nurs Sci 2009;11(2):143-148 (Korean).

15. Lawshe $\mathrm{CH}$. A quantitative approach to content validity 1. Pers Psychol 1975;28(4):563-575.
16. Lee S. A study on the usefulness of Delphi technology prediction technique [dissertation]. Jeonju: Jeonbuk National University; 2002 (Korean).

17. Sullivan GM, Artino AR Jr. Analyzing and interpreting data from likert-type scales. J Grad Med Educ 2013;5(4):541-542.

18. Boone HN, Boone DA. Analyzing Likert data. J Ext 2012;50(2): 2TOT2.

19. Fu YC, Wang DW, Chuang JH. Representative contact diaries for modeling the spread of infectious diseases in Taiwan. PLoS One 2012;7(10):e45113.

20. Read JM, Lessler J, Riley S, Wang S, Tan LJ, Kwok KO, et al. Social mixing patterns in rural and urban areas of southern China. Proc Biol Sci 2014;281(1785):20140268.

21. Oh HS, Yang YR, Ryu MK, Shin MJ, Kim JS. Analysis of transmission patterns of infection according to contact behavior in daily life. Cheongju: Korea Centers for Disease Control and Prevention; 2017, p. 151 (Korean). 